\title{
Reply to: "Accuracy of CSF Lactate for Neurologic Outcome in Survivors of Cardiac Arrest"
}

\author{
Seung Ha Son ${ }^{1}$, Yong Nam In ${ }^{2,3}$ and Jung Soo Park ${ }^{1,3^{*}}$ (D) \\ (0) 2021 Springer Science+Business Media, LLC, part of Springer Nature and Neurocritical Care Society
}

We thank Dr. Justin H. Granstein and colleagues for their interest in our article and appreciate their comments on electroencephalography (EEG) for monitoring elevation in lactate levels due to seizures.

The seizures were obscured by the use of a neuromuscular blocker. Therefore, we applied Bispectral Index (BIS monitor; Covidien) monitoring to determine whether the patient was experiencing seizures [1]. However, elevated lactate levels, whether elevated because of the seizures or anaerobic metabolism, are associated with poor prognosis [2]. Elevated lactate levels due to seizures normalize within a few hours [3].

As mentioned in the Discussion section [4], the key point in this study is that lactate can be used as an energy fuel in groups with good neurologic outcome. Therefore, we presented the arterio-cerebrospinal fluid difference in the lactate.

We suggest that EEG is a very significant modality for predicting the neurologic prognosis of survivors of cardiac arrest. Recently, we applied amplitude-integrated EEG to survivors of cardiac arrest. As you mentioned, we expect that if biomarkers and EEG are applied together, the patient's prognosis can be predicted more accurately.

\footnotetext{
*Correspondence: cpcr@cnu.ac.kr

${ }^{1}$ Department of Emergency Medicine, Chungnam National University Hospital, 282, Munhwa-ro, Jung-gu, Daejeon, Republic of Korea

Full list of author information is available at the end of the article
}

\begin{abstract}
Author details
1 Department of Emergency Medicine, Chungnam National University Hospital, 282, Munhwa-ro, Jung-gu, Daejeon, Republic of Korea. ${ }^{2}$ Department of Emergency Medicine, Chungnam National University Sejong Hospital, 20, Bodeum 7-ro, Sejong, Republic of Korea. ${ }^{3}$ Department of Emergency Medicine, College of Medicine, Chungnam National University, 282, Mokdong-ro, Jung-gu, Daejeon, Republic of Korea.
\end{abstract}

\section{Funding}

The authors received no support for this article.

Conflicts of interest

The authors declare no conflicts of interest.

\section{Publisher's Note}

Springer Nature remains neutral with regard to jurisdictional claims in published maps and institutional affiliations.

Received: 10 March 2021 Accepted: 18 March 2021

Published online: 18 May 2021

\section{References}

1. Haesen J, Eertmans W, Genbrugge C, Meex I, Demeestere J, Vander Laenen $M$, et al. The validation of simplified EEG derived from the bispectral index monitor in post-cardiac arrest patients. Resuscitation. 2018;126:179-84.

2. Westhall E, Rossetti AO, van Rootselaar AF, Wesenberg Kjaer T, Horn J, Ullén $\mathrm{S}$, et al. Standardized EEG interpretation accurately predicts prognosis after cardiac arrest. Neurology. 2016:86(16):1482-90.

3. Nass RD, Zur B, Elger CE, Holdenrieder S, Surges R. Acute metabolic effects of tonic-clonic seizures. Epilepsia Open. 2019:4(4):599-608.

4. Son SH, In YN, Park JS, You Y, Min JH, Yoo I, et al. Cerebrospinal fluid lactate levels, brain lactate metabolism and neurologic outcome in patients with out-of-hospital cardiac arrest. Neurocrit Care. 2021. https://doi.org/10. 1007/s12028-020-01181-1.

This article is related to the original article available at https://link.sprin ger.com/article/10.1007/s12028-020-01181-1. This article is a response to the Letter to the Editor available at https://link.springer.com/article/10. 1007/s12028-021-01238-9.

\section{Springer}

